\title{
CONCENTRATION OF HYDROGEN IONS IN SALIVA, AND SOME RECENT METHODS OF SALIVARY ANALYSIS ${ }^{1}$
}

\author{
H. CARLTON SMITH
}

Harvard University Dental School, Boston, Massachusetts

CONTENTS

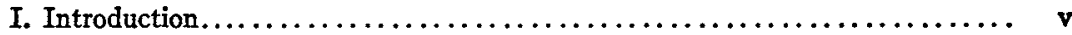

II. Determinations of the concentration of hydrogen ions $(\mathrm{pH})$ in saliva, and the significance of knowledge on this point. ................... vi

III. On the role of proteins in tartar formation. $\ldots \ldots \ldots \ldots \ldots \ldots \ldots \ldots \ldots \ldots$ vili

IV. Miscellaneous observations..........................

\section{INTRODUCTION}

I appreciate the fact that it is very bad form to offer apologies or make excuses, and consequently offer you one or two at the outset tonight. The first is very well put in one of the parables of "Safed the Sage" which some of you may recall. It runs as follows: ${ }^{2}$

"There came to the City wherein I dwell a man who delivered a Lecture, and I and Keturah we went. And the subject whereof he spake was one about which he knew very little. But he spread that little over the surface of an Interesting Talk, and the people enjoyed it, and so did we. Yea, and we were profited thereby, although the Lecturer knew little more than he told us.

"And there came another man who spake on the same subject, and we went to hear him. And he was a man of Great Erudition. And I said, Now Shall we hear something Worth While.

"But he began by telling us the History of the Subject and the Various Attempts to Elucidate it. And then he spake of the Various Theories that had been suggested concerning it, and the books that had been written in Divers Tongues with regard to it. And he said that a certain opinion had been held by men of learning, but was now no longer highly regarded, but that the opinion that was to take its place was in dispute. And he suggested Various Aspects of the theme which he said he could not Discuss because it would require a Volume on any one of them. And about that time it was time to stop, and he stopped.

"And as we journeyed toward our home, Keturah said, He certainly is a man of large knowledge. And I answered, Yea, and for the purposes of that audience it were better if he had known the tenth part of what he knoweth. For the first man carried all his

1 Read at a meeting of the American Academy of Dental Science, Boston, Massachusetts, March 2, 1921.

${ }^{2}$ Congregationalist and Advance, July 31, 1919. 
goods in his show window, and this man blocked the sidewalk with dray-loads of unopened cases and bales of wisdom.

"And Keturah said, I have heard that a Little Knowledge is a Dangerous thing. And I said, Believe it not. A little knowledge is good for seed, but there is such a thing as that a man getteth drowned in his own knowledge. For the first man knew little, but used that little effectively, and the second man knew much, and it was useless."

I know so little about the subject that I hope our evening together will be at least interesting. Please note the point made by the parable: that a little knowledge is good for seed.

My second excuse for taking your time this evening, with what is practically a school lecture, is the fact that most of us graduated several years ago and I realize how impossible it is for busy practitioners to keep thoroughly posted on all lines of investigation.

II. DETERMTNATIONS OF THE CONCENTRATION OF HYDROGEN IONS (pH) IN SALIVA, AND THE SIGNIFICANCE OF KNOWLEDGE ON THIS POINT

In a very valuable paper on salivary analysis, by Dr. H. C. Ferris, in the Dental Cosmos for April, 1920, the statement is made that "the free acid findings are the most valuable." Leaving out the word "free" because I am not sure just what he means by it, I agree with Dr. Ferris perfectly. Because of my feeling that the acid findings are as important as those of any one test we make, I propose to spend a considerable portion of our time upon this subject of acidity. In order that we may all have the same conception of what we mean by the term, I would define acidity as the condition produced by the presence of free hydrogen ions.

This term "ion" is perfectly familiar. We have read and talked about "ionic" medication for years, yet it was not long ago that I read, in Dental Items of Interest $\mathrm{I}$ think, a criticism of a writer who referred to ionization as being caused by a current of electricity. A very valuable article in Dental Cosmos about a year ago, gives a perfectly clear and correct explanation of ionization; and then in the next paragraph goes on, in further explanation, to leave the same impression, namely, that a current of electricity is a necessary factor in producing ionization, although the statement is not made. Now ionization (dissociation, demonstrated in 1885 by Arrhenius, a Swedish chemist) exists independently of any current of electricity from outside sources, the change being brought about by the action of the solvent. The ions carry positive and negative charges of electricity to be sure, but this condition results from an interchange of electrons and not to extraneous currents. 
In a solution of a salt or an acid only a part, perhaps a small proportion, of the number of molecules is ionized at a given time; and it is only the ionized molecules which are chemically active. This is a very important fundamental; and because chemists, dentists and others have overlooked the fact, many errors have been made in our past work.

Now let us consider the acidity of saliva. We have been in the habit of determining the degree of acidity by titration, i.e., by measuring the acid strength of an unknown by neutralizing with an alkaline solution of known strength. Now what happens during an ordinary titration? The few ionized molecules of acid react with the alkali, and produce salt and water; then more of the acid molecules become dissociated, and a further reaction with the alkali takes place; and so on till all of the acid is used up. We determine the total amount of acid in our solution in this way, but we know nothing of the existing acid condition of our solution at the time we started the titration, i.e., the proportion of the molecules that were then in ionized condition.

The existing acid condition is important and so we seek to determine this by ascertaining the concentration of hydrogen ions, which is the true acidity according to our definition. It is well known that hydrochloric acid dissociates to a much greater extent than does acetic; so, if we had a $\frac{\mathrm{N}}{\mathrm{I}}$ solution of each of these (titratable acid strength being the same), we should find that the concentration of hydrogen ions or "existing acidity" of the hydrochloric acid solution is something like seventy times as great as that of the acetic.

In the practical application of these facts to saliva we have found that, in the great majority of cases thus far examined, the saliva in erosion (not mechanical) showed a hydrogen-ion value below 7 and also a permanent acidity (i.e., not entirely due to $\mathrm{CO}_{2}$ ) when titrated with phenolthalein as indicator. Salivas from pyorrhea patients show low concentration of hydrogen ion, though perhaps not particularly acid. Normal saliva has a hydrogen ion concentration around 7.25 , of course with reasonable latitude. This is a little lower than the normal hydrogen-ion value for blood, which is about 7.33. In mouths where tartar is prevalent, the saliva shows a hydrogen-ion concentration of from 7.4 to 7.6 , with very rare exceptions.

The facility with which microörganisms develop in the saliva has for many years been recognized as having an important bearing on the health of the oral tissue, and it is now known that this facility is dependent upon the $\mathrm{pH}$ of the media, hence an added importance attaches itself to this determination. To be sure, much has to be learned in regard to the detail of the procedure and the significance of results. 
In emphasizing the concentration of hydrogen ions in the analysis of saliva, I have sought to bring to your attention an additional test which promises to be of great value. The details of older tests have been omitted as taking an unnecessary amount of your time.

\section{ON THE RÔLE OF PROTEINS IN TARTAR FORMATION}

In regard to tartar formations: in the issue of Science, for November 12, 1920 , there appeared an intensely interesting article by Dr. Loeb of the Rockefeller Institute for Medical Research, on "proteins and colloid chemistry." If you read the article you will recall that the paper showed that "proteins exist in three states, defined by their hydrogen-ion concentration" (I am quoting Dr. Loeb):

“(a) As non-ionogenic or isoelectric protein, (b) metal proteinate (e.g., sodium or calcium proteinate), and (c) protein-acid salts (e.g., protein chloride, protein sulfate, etc.). We will use gelatin as an illustration. At one definite hydrogen-ion concentration, namely, pH 4.7, gelatin can combine practically with neither anion nor cation of an electrolyte. At a $\mathrm{pH}$ greater than 4.7 , it can combine only with cations, i.e., basic or metallic ions (forming metal gelatinate, e.g., sodium gelatinate); at a pH less than 4.7 it combines with anions (forming gelatin chloride, etc.). This was proved in the following way: different doses of $1 \mathrm{gm}$. of gelatin each possessing a different $\mathrm{pH}$ were put for one hour into beakers containing the same concentration of silver nitrate at a temperature of $15^{\circ} \mathrm{C}$. They were then put on a filter and washed six or eight times each with $25 \mathrm{cc}$. of ice cold water (the wash water must be cold since otherwise the particles will coalesce and the washing will be incomplete). This washing serves the purpose of removing the silver nitrate held in solution between the granules, thus allowing us to ascertain where the silver is in combination with gelatin and where it is not in combination, since the silver not in combination with gelatin can be removed by the washing while the former can not, or at least only extremely slowly by altering the hydrogen ion. After having removed the silver nitrate not in combination with gelatin by washing with ice-cold water, we melt the gelatin by heating to $40^{\circ} \mathrm{C}$., adding enough distilled water to bring the volume of each gelatin solution to $100^{\circ} \mathrm{cc}$., determine the $\mathrm{pH}$ of each solution potentiometrically or colorimetrically, and expose the solution in test tubes to light, the previous manipulations having been carried out in a dark room (with the exception of the determination of $\mathrm{pH}$, for which only part of the gelatin solution was used). In twenty minutes all the gelatin solutions with $\mathrm{pH}$ greater than 4.7 , i.e., from $\mathrm{pH} 4.8$ and above, become opaque and then black, while all the solutions of $\mathrm{pH}$ less than 4.7 , i.e., from 4.6 and below, remain transparent even when exposed to light for months or years. The solutions of $\mathrm{pH} 4.7$ become opaque, but remain white, no matter how long they may have been exposed to light. At this $\mathrm{pH}$-the isoelectric point-gelatin is not in combination with silver, but it is insoluble. Hence the cation of silver is only in chemical combination with gelatin when the $\mathrm{pH}$ is greater than 4.7. At pH 4.7 or below, gelatin is not able to combine with silver ionogenically. This statement was confirmed by volumetric analysis."

It occurred to me that, if this is true of gelatin, why not of the salivary proteins. (Dr. Loeb draws his conclusions in regard to proteins in general.) 
Dr. Gies, of Columbia, is authority for the statement that mucin will combine with one, two or more atoms of sodium, calcium and other cations, forming mucinates of variable degrees of acidity.

To answer some of the questions suggested by the foregoing data, the following experiment was performed: Saliva, presumably normal and capable of producing tartar in moderate amount with a $\mathrm{pH}$ of 7.4 (slightly alkaline), was thoroughly dialyzed for 48 hours, when all traces of chlorides or phosphates had disappeared, at least so far as chemical tests would show. The $\mathrm{pH}$ of this dialyzed saliva was now 6.8 or very faintly acid, due to the acid properties of the salivary proteins. This was next shaken with calcium carbonate free from soluble alkali and thoroughly centrifugalized. The clear supernatant fluid was now absolutely neutral. I assume that the calcium had combined with the acid protein.

This neutralized saliva was divided into two parts. To one part was added a little sodium bicarbonate and sodium acid phosphate, bringing the $\mathrm{pH}$ to 7.6. In each of these portions was placed a freshly extracted and carefully weighed tooth. After four days-not a great while for tartar to deposit- the teeth were again carefully weighed. The one in the neutral saliva weighed exactly the same to the tenth of a milligram, while the other tooth had gained 5 milligrams. The teeth were weighed each time in distilled water and the saliva preserved with a small crystal of thymol.

The fact that proteins will hold inorganic salts in solution has long been recognized. Dr. Percy Howe told the Academy of Stomatology of Philadelphia, seven years ago this month (March 28,1914), that in his experience the proteins of the saliva "hold the crystalloids in solution in from two to four times their water solubilities" and makes calcium oxide a definite example. Dr. Black in his Special Dental Pathology makes a similar statement (page 98 of the 1920 edition), in which he refers to the calcium being held by salivary globulin. I believe that salivary proteins or colloids would be preferable terms.

The obvious conclusion to the foregoing, it seems to me, is that, in the study of tartar, we must consider the protein content of saliva and the concentration of hydrogen ions in the sample as well as the older factors of the relative amounts of calcium carbonate and phosphates.

\section{MISCELIANEOUS OBSERVATIONS}

The electrical conductivity of samples of saliva has been determined by Louis Barrett and L. E. Flagg of our sophomore class. The relation is not well marked, but, in general, pyorrheal saliva has a higher conductivity (0.0016 to 0.0090$)$. In pronounced cases, the high conductivity is accom- 
panied by a low $\mathrm{pH}$. In typical caries the conductivity runs lower: 0.0005 to 0.0029 (ages 25 and up).

The hypobromite method for the determination of urea in urine (much more accurate for this purpose than some suppose) is not accurate for saliva, since ammonium chloride is decomposed and gives off nitrogen gas; and in saliva, ammonium chloride is often present in a quantity similar to that of urea itself. We are determining urea in saliva by converting the urea into ammonia, which is then conducted by means of an air current into a known volume of standard acid solution. The excess of acid is then titrated. Urea exists normally in the saliva to the extent of 9-14 mgm. per $100 \mathrm{cc}$. In all cases of nephritis we find it to run much higher, as might be expected, in some of the most severe cases reaching 50 or $60 \mathrm{mgm}$. per $100 \mathrm{cc}$.

Creatinine is being determined by the picric-acid method, with a Duboscq colorimeter. It is interesting to note that with both the urea and the creatinine, the rise in cases of nephritis follows very closely that of the blood.

Uric acid is regularly tested for by Dr. Folin's phosphotungstic acid method and is almost always found to be present.

There is one other condition to which I wish to call your attention, and to which reference has already been made, and that is the temporary, permanent, and progressive acidities found in different salivas.

Temporary acidity is that which can be made entirely to disappear by boiling alone. This I assume to be principally due to carbon dioxide and is a normal condition.

Permanent acidity is such that after prolonged boiling the sample is still found to be acid. In many of these cases, where acid lactates have been indicated by the polarized-light picture, lactic acid has been separated by ether and identified by chemical tests.

"Progressive acidity" is the term we have applied to cases in which the degree of acidity increases with boiling. The longer the saliva is kept at the boiling point, the greater the acidity. Dr. Gies has suggested an explanation of this condition by assuming that calcium is present combined with phosphoric acid and held in solution by colloidal protein, and that from this combination the prolonged boiling separates basic calcium phosphate, as in the case of urine under similar circumstances.

We believe this particular phenomenon should be thoroughly investigated in reference to tartar formation. 